\title{
Antithrombin levels during pediatric cardiopulmonary bypass: Key to changing a decades-old paradigm for anticoagulation?
}

\author{
Dean B. Andropoulos, MD, MHCM, ${ }^{\mathrm{a}, \mathrm{b}, \mathrm{c}}$ and Charles D. Fraser, Jr, MD
}

\footnotetext{
From the ${ }^{\mathrm{a} D i v i s i o n}$ of Pediatric Cardiovascular Anesthesiology, Texas Children's Hospital; the ${ }^{\mathrm{b}}$ Department of Pediatrics, Baylor College of Medicine, Houston, Tex; and the ${ }^{\mathrm{c} D e p a r t m e n t ~ o f ~ A n e s t h e s i o l o g y, ~ B a y l o r ~ C o l l e g e ~}$ of Medicine, Houston, Tex; the ${ }^{\mathrm{d}}$ Department of Surgery, Texas Children's Hospital, Houston, Tex; and the ${ }^{\mathrm{e}}$ Department of Surgery, Baylor College of Medicine, Houston, Tex.

Disclosures: Authors have nothing to disclose with regard to commercial support.

Received for publication Oct 13, 2015; accepted for publication Oct 18, 2015; available ahead of print Nov 11, 2015.

Address for reprints: Dean B. Andropoulos, MD, MHCM, Texas Children's Hospital, Department of Anesthesiology, 6621 Fannin St, W 17417, Houston, TX 77030 (E-mail: dra@bcm.edu or dra@bcm.tmc.edu).

J Thorac Cardiovasc Surg 2016;151:305-6

$0022-5223 / \$ 36.00$

Copyright (C) 2016 by The American Association for Thoracic Surgery

http://dx.doi.org/10.1016/j.jtcvs.2015.10.042
}

In 1959, Drs Arthur Keats, Denton Cooley, and Janet Telford from Texas Children's Hospital and Baylor College of Medicine published their landmark article in The Journal of Thoracic and Cardiovascular Surgery describing dose titration of heparin for anticoagulation for cardiopulmonary bypass (CPB) and protamine for its reversal. They reported that $1.5 \mathrm{mg}$ of protamine per $1 \mathrm{mg}$ (100 units) of heparin resulted in effective heparin neutralization after bypass in infants, children, and adults undergoing surgery for congenital heart disease. ${ }^{1}$ This study laid the foundation for subsequent practice in infants and children, with an initial heparin dose of 300 to 400 units $/ \mathrm{kg}$ used to achieve and maintain an activated clotting time of 400 to 480 seconds and reversal of heparin with 1.0 to $1.5 \mathrm{mg}$ of protamine for every 100 units of the original heparin dose. Remarkably, despite subsequent refinements in anticoagulation monitoring, including indirect plasma heparin assay (Hepcon; Medtronic Corporation, Minneapolis, Minn) and thromboelastography adopted by some centers, the basic approach to heparin and protamine dosing has remained unchanged for more than 50 years. ${ }^{2}$ The simplicity and efficacy of this approach in the complex milieu of infant CPB is the major reason for the persistence of this practice. Despite this longstanding approach, however, both thrombotic and bleeding complications after surgery with CPB occur with an incidence of greater than $25 \%$ in infants younger than 1 year.

Antithrombin is a 432-amino acid glycoprotein synthesized in the liver that plays an important role in the delicate balance between thrombosis and maintenance of blood flow by inactivating its target enzymes, including thrombin and factor $\mathrm{Xa}$ (Figure 1). ${ }^{4}$ Antithrombinthrombin binding occurs normally at a low baseline level; when heparin binds covalently to antithrombin, thrombin inhibition is increased 2000- to 4000-fold to enable anticoagulation for CPB and other therapeutic uses.

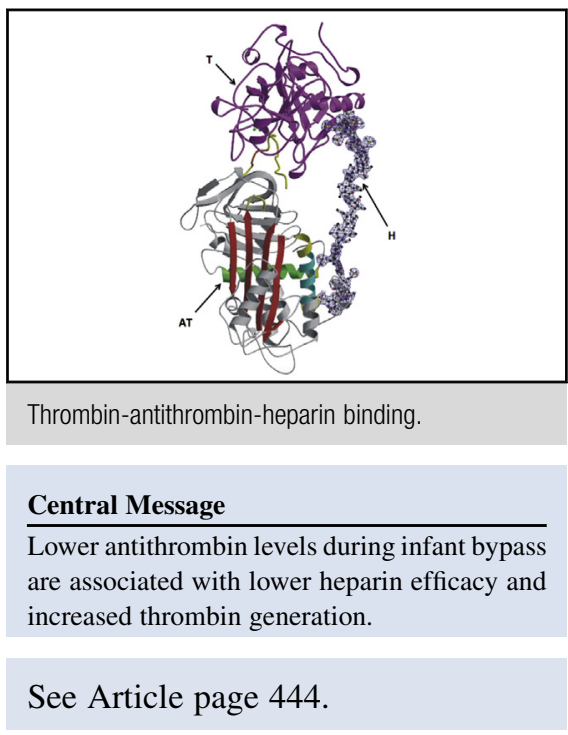

Plasma antithrombin levels are approximately $60 \%$ of adult levels in the neonatal period and increase to nearly adult levels by 6 months of age. ${ }^{5}$

In this issue of the Journal, Manlhiot and colleagues ${ }^{6}$ have made a significant contribution to our understanding of antithrombin levels and heparin efficacy during CPB in infants. They performed a secondary analysis of data from a study of Hepcon versus standard management of heparinization in 90 infants younger than 1 year. $^{7}$ In that earlier article, they had reported reductions in bleeding, transfusion, ventilation time, and intensive care unit and hospital stays with individualized anticoagulation management with Hepcon. In their article in this issue, Manlhiot and colleagues ${ }^{6}$ analyzed antithrombin levels from the same subjects that were measured at baseline, at the end of CPB, and 24 hours postoperatively. Lower baseline antithrombin activity was associated with lower anti-factor Xa activity after heparin and with a larger total heparin dose. Lower antithrombin was also associated with higher levels of thrombin-antithrombin complex, prothrombin activation fragment, and D-dimer levels. These findings persisted after multivariable adjustment for patient age, duration of CPB, and amount of fresh-frozen plasma used during CPB. The major interpretation of these findings is that lower antithrombin levels are associated with lower heparin efficacy, leading to increased thrombin generation during CPB. Suppressing thrombin generation during $\mathrm{CPB}$ is an important goal, because increased thrombin generation leads to 


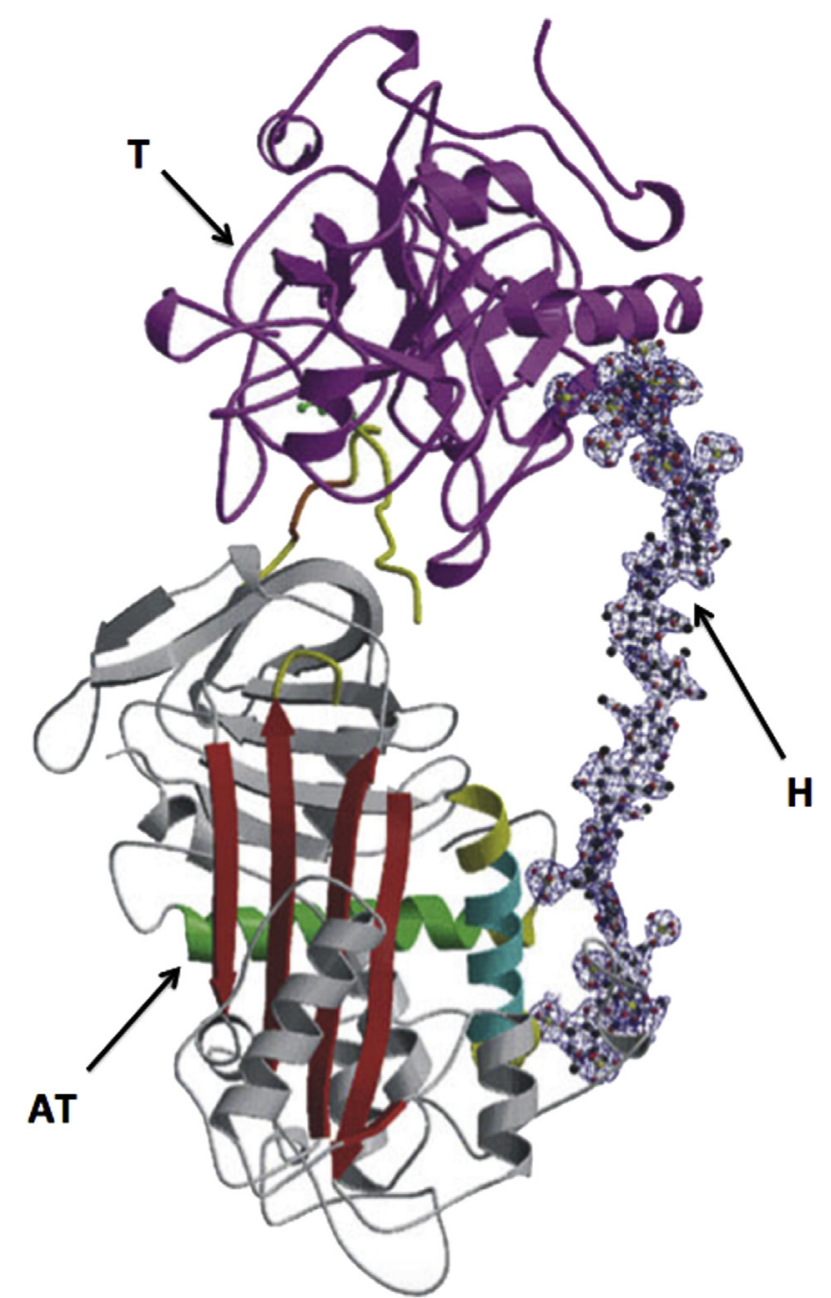

FIGURE 1. Binding of antithrombin (AT), thrombin $(T)$, and heparin $(H)$. (Reproduced with permission of Nature Publishing Group from Li W, Johnson DJ, Esmon CT, Huntington JA. Structure of the antithrombinthrombin-heparin ternary complex reveals the antithrombotic mechanism of heparin. Nat Struct Mol Biol. 2004;11:857-62.)

increased fibrinogen consumption and increased fibrinolysis, which can in turn increase bleeding and blood transfusion. ${ }^{8}$ Analyzing antithrombin levels and their effect on heparin efficacy was not the aim of the original study, and in this more recent analysis Manlhiot and colleagues ${ }^{6}$ did not correlate antithrombin levels with perioperative bleeding, transfusion, and other clinical outcomes. Nonetheless, they have provided important insight into the role of antithrombin in infant cardiac surgery. As stated in the article, they have provided the rationale for an antithrombin replacement trial, with the aim of determining whether this approach will individualize and improve anticoagulation during CPB in infants.

Antithrombin replacement has been used for the past decade in anticoagulation protocols for extracorporeal life support in pediatric patients, with the goal of increasing heparin efficacy. ${ }^{9}$ Ryerson and colleagues ${ }^{10}$ reported on the administration of high-dose antithrombin to 36 infants on extracorporeal life support, which resulted in more than doubling of the plasma antithrombin level and near doubling of the anti-factor Xa level, with a subsequent decrease in heparin dose requirements and without adverse events. ${ }^{10}$ Antithrombin supplementation has also been reported in several small adult CPB studies. Ranucci and colleagues $^{11}$ performed a randomized, controlled trial of preoperative antithrombin supplementation in adult CPB surgery. Heparin resistance rate decreased from $38 \%$ to $17 \%$, with no clinical differences in bleeding or transfusion rates. Finally, a recent multidisciplinary panel of experts in congenital heart disease that was convened to recommend high-impact clinical studies recognized antithrombin supplementation as a potential area of investigation in pediatric CPB. ${ }^{12}$ Manlhiot and colleagues ${ }^{6}$ have provided a rationale for such an experimental approach, which could potentially result in a major practice change in the decades old paradigm for infant $\mathrm{CPB}$, for example to antithrombin replacement plus heparin.

\section{References}

1. Keats AS, Cooley DA, Telford J. Relative antiheparin potency of polybrene and protamine in patients undergoing extracorporeal circulation. $J$ Thorac Cardiovasc Surg. 1959;38:362-8.

2. Gertler R, Andropoulos DB. Cardiopulmonary bypass. In: Andropoulos DB, Stayer SA, Mossad EB, Miller-Hance WC, eds. Anesthesia for congenital heart disease. 3rd ed. Oxford, UK: Wiley-Blackwell; 2015:127-55.

3. Manlhiot C, Menjak IB, Brandão LR, Gruenwald CE, Schwartz SM, Sivarajan VB, et al. Risk, clinical features, and outcomes of thrombosis associated with pediatric cardiac surgery. Circulation. 2011;124:1511-9.

4. Li W, Johnson DJ, Esmon CT, Huntington JA. Structure of the antithrombinthrombin-heparin ternary complex reveals the antithrombotic mechanism of heparin. Nat Struct Mol Biol. 2004;11:857-62.

5. Andrew M, Paes B, Milner R, Johnston M, Mitchell L, Tollefsen DM, et al. Development of the human coagulation system in the full-term infant. Blood. 1987;70:165-72.

6. Manlhiot C, Gruenwald CE, Holtby HH, Brandão LR, Chan AK, Van Arsdell GS, et al. Challenges with heparin-based anticoagulation during cardiopulmonary bypass in children: impact of low antithrombin activity. J Thorac Cardiovasc Surg. 2016;151:444-50.

7. Gruenwald CE, Manlhiot C, Chan AK, Crawford-Lean L, Foreman C, Holtby HM, et al. Randomized, controlled trial of individualized heparin and protamine management in infants undergoing cardiac surgery with cardiopulmonary bypass. J Am Coll Cardiol. 2010;56:1794-802.

8. Miller BE, Guzzetta NA, Williams GD. Coagulation, cardiopulmonary bypass, and bleeding. In: Andropoulos DB, Stayer SA, Mossad EB, Miller-Hance WC, eds. Anesthesia for congenital heart disease. 3rd ed. Oxford, UK: Wiley-Blackwell; 2015:295-312.

9. Annich G, Adachi I. Anticoagulation for pediatric mechanical circulatory support. Pediatr Crit Care Med. 2013;14(5 Suppl 1):S37-42.

10. Ryerson LM, Bruce AK, Lequier L, Kuhle S, Massicotte MP, Bauman ME. Administration of antithrombin concentrate in infants and children on extracorporeal life support improves anticoagulation efficacy. ASAIO J. 2014;60:559-63.

11. Ranucci M, Baryshnikova E, Crapelli GB, Woodward MK, Paez A, Pelissero G Preoperative antithrombin supplementation in cardiac surgery: a randomized controlled trial. J Thorac Cardiovasc Surg. 2013;145:1393-9.

12. Kaltman JR, Andropoulos DB, Checchia PA, Gaynor JW, Hoffman TM, Laussen PC, et al; Perioperative Working Group. Report of the Pediatric Heart Network and National Heart, Lung, and Blood Institute Working Group on the Perioperative Management of Congenital Heart Disease. Circulation. 2010; 121:2766-72. 